\title{
Sensitization to shrimp and house dust mites in a Swedish population-based study: Influence on allergic disorders and lung function
}

\author{
Ida Waern ${ }^{1}$, Magnus Molin ${ }^{2}$, Robert Moverare ${ }^{2}$, Jonas Lidholm², Andrei Malinovschi ${ }^{3}$, \\ Magnus Borres ${ }^{2}$, and Christer Janson ${ }^{4}$ \\ ${ }^{1}$ Sveriges lantbruksuniversitet \\ ${ }^{2}$ Thermo Fisher Scientific Inc Sweden \\ ${ }^{3}$ Uppsala Universitet Jamforande fysiologi \\ ${ }^{4}$ Uppsala universitet Institutionen for medicinska vetenskaper
}

January 21, 2022

\section{Sensitization to shrimp and house dust mites in a Swedish population-based study: Influence on allergic disorders and lung function}

Ida Waern ${ }^{1}$, Magnus Molin ${ }^{2}$, Robert Movérare ${ }^{2,3}$, Jonas Lidholm² ${ }^{2}$ Andrei Malinovschi ${ }^{4}$, Magnus P. Borres ${ }^{2,5}$, Christer Janson ${ }^{3}$.

${ }^{1}$ Department of Anatomy, Physiology and Biochemistry, Swedish University of Agricultural Sciences, Uppsala, Sweden

${ }^{2}$ Thermo Fisher Scientific, Uppsala, Sweden

${ }^{3}$ Department of Medical Sciences: Respiratory, Allergy and Sleep Research, Uppsala University, Uppsala, Sweden

${ }^{4}$ Department of Medical Sciences: Clinical Physiology, Uppsala University, Uppsala, Sweden

${ }^{5}$ Department of Maternal and Child Health, Uppsala University, Uppsala, Sweden

Correspondence

${ }^{1}$ Ida Waern, Department of Anatomy, Physiology and Biochemistry, Swedish University of Agricultural Sciences, BOX 7011, SE-75007 Uppsala, Sweden, +46 186728 19,Ida.Waern@slu.se

\section{To the Editor,}

Shrimp allergy is one of the most prevalent food allergies and a major shrimp allergen is the muscle protein tropomyosin (Pen a 1). In a Swedish study of young asthmatics, 15\% were sensitized to shrimp and $8 \%$ reported symptoms of shrimp hypersensitivity ${ }^{1}$. House dust mites are one of the most common allergens to which asthmatic patients are sensitized ${ }^{2}$. Tropomyosin has been identified as an allergen in house dust mites, insects, and molluscs, making it likely that patients sensitized to shrimp and house dust mites are also at risk of cross-reactions to tropomyosin from other species. Allergic reactions mediated by cross-reactive IgE can occur in individuals primarily sensitized to airborne allergens, who also show sensitivity to proteins present in food. It has been shown that IgE from shrimp allergic patients can recognize proteins from insect extracts $^{3}$. 
In this study, we assessed the prevalence of shrimp and house dust mite sensitization in a large populationbased study and compared IgE sensitization in relation to allergic disorders and respiratory symptoms. Chi-squared test and ANOVA was used to detect group differences in univariate analyses, while logistic and linear regression was used in adjusted analyses.

A total of 4593 randomly selected adult subjects aged 50-64 years from the Swedish CArdioPulmonary bioImage Study (SCAPIS, Uppsala cohort) took part in an extensive questionnaire, blood sampling, physical examinations, lung function tests, and imaging ${ }^{4,5}$. IgE sensitization was defined as having specific IgE [?]0.35 $\mathrm{kU}_{\mathrm{A}} / \mathrm{L}$, measured by ImmunoCAP (Thermo Fisher Scientific, Uppsala, Sweden). Forced expiratory volume in one second $\left(\mathrm{FEV}_{1}\right)$ and forced vital capacity $(\mathrm{FVC})$ after bronchodilation were measured. Chronic airflow limitation $(\mathrm{CAL})$ was defined as having $\mathrm{FEV}_{1} / \mathrm{FVC}$ ratio $<0.70$.

Of all participants, 253 (5.5\%) were IgE-sensitized to shrimp ([?]0.35 $\left.\mathrm{kU}_{\mathrm{A}} / \mathrm{L}\right), 191$ (4.2\%) to mites, and 104 $(2.3 \%)$ to both allergens. Of the shrimp-sensitized patients, $41 \%$ were also sensitized to mites, while $54 \%$ of the mite-sensitized patients were also sensitized to shrimp.

Participants with complete IgE results $(\mathrm{n}=4593)$ were divided into four groups based on sensitization to shrimp, house dust mites, both shrimp and house dust mites, or neither allergen (see Table 1 for details). Significant group differences were found regarding prevalence of asthma, allergic rhinitis, urticaria, angioedema, wheeze, $\mathrm{FEV}_{1}$ and $\mathrm{CAL}$.

Table 1. Characteristics of study groups defined by sensitization to shrimp and/or house dust mite (\% and mean+-SD)

\begin{tabular}{|c|c|c|c|c|c|}
\hline & $\begin{array}{l}\text { Non-sensitized } \\
(\text { shrimp or mite) } \\
(\mathrm{n}=4253)\end{array}$ & $\begin{array}{l}\text { Only shrimp- } \\
\text { sensitized } \\
(\mathrm{n}=149)\end{array}$ & $\begin{array}{l}\text { Only mite- } \\
\text { sensitized } \\
(\mathrm{n}=87)\end{array}$ & $\begin{array}{l}\text { Sensitized to } \\
\text { both shrimp and } \\
\text { mites }(n=104)\end{array}$ & $p$-value \\
\hline Women (\%) & 52.6 & 38.3 & 43.7 & 43.3 & 0.001 \\
\hline Age (yrs) & $57.7 \pm 4.4$ & $57.9 \pm 4.2$ & $56.9 \pm 4.8$ & $57.3 \pm 4.6$ & 0.27 \\
\hline Asthma (\%) & 5.7 & 5.0 & 17.1 & 16.5 & $<0.0001$ \\
\hline $\begin{array}{l}\text { Allergic } \\
\text { rhinitis (\%) }\end{array}$ & 19.9 & 28.3 & 46.2 & 34.8 & $<0.0001$ \\
\hline Urticaria (\%) & 26.5 & 35.6 & 44.9 & 36.4 & $<0.0001$ \\
\hline $\begin{array}{l}\text { Angioedema } \\
(\%)\end{array}$ & 5.2 & 9.7 & 11.4 & 13.2 & $<0.0001$ \\
\hline Wheeze (\%) & 6.4 & 5.0 & 9.9 & 16.3 & 0.001 \\
\hline $\begin{array}{l}\mathrm{FEV}_{1} \% \\
\text { predicted (\%) }\end{array}$ & $109 \pm 14$ & $109 \pm 15$ & $110 \pm 13$ & $105 \pm 15$ & 0.02 \\
\hline CAL (\%) & 7.4 & 4.8 & 6.1 & 15.2 & 0.02 \\
\hline
\end{tabular}

Being sensitized to both shrimp and mites was independently associated with having angioedema, wheeze, and chronic airflow limitation, after adjusting for age, sex, and birch and cat sensitization. Being sensitized to shrimp or mite alone was associated with having urticaria (Table 2). There was also an independent association between lower $\mathrm{FEV}_{1}$ (\% of predicted) and sensitization to both shrimp and mites: -3.5 (-6.5, $-0.5) \%$ of predicted units.

Table 2. Logistic regression adjusted for age, sex, and sensitization to birch and cat (odds ratio, $95 \%$ confidence interval)

\begin{tabular}{llll}
\hline & Only shrimp & Only mites & Both \\
\hline Asthma & $0.60(0.27-1.34)$ & $1.82(0.95-3.48)$ & $1.67(0.88-3.17)$ \\
Allergic rhinitis & $1.01(0.65-1.56)$ & $1.64(0.97-2.80)$ & $0.91(0.54-1.53)$
\end{tabular}




\begin{tabular}{llll}
\hline & Only shrimp & Only mites & Both \\
\hline Urticaria & $\mathbf{1 . 5 5}(\mathbf{1 . 0 5 - 2 . 2 8})$ & $\mathbf{2 . 1 9} \mathbf{( 1 . 3 3 - 3 . 6 0 )}$ & $1.49(0.93-2.41)$ \\
Angioedema & $1.66(0.88-3.86)$ & $1.83(0.87-3.86)$ & $\mathbf{2 . 2 8}(\mathbf{1 . 1 8 - 4 . 3 9 )}$ \\
Wheeze & $0.70(0.32-1.52)$ & $1.36(0.63-2.92)$ & $\mathbf{2 . 4 7}(\mathbf{1 . 3 6}-\mathbf{4 . 4 7})$ \\
CAL & $0.57(0.26-1.24)$ & $0.81(0.32-2.05)$ & $\mathbf{2 . 0 3}(\mathbf{1 . 1 1 - 3 . 7 1})$ \\
\hline
\end{tabular}

The main finding of this study was that approximately half of those with IgE sensitization to shrimp were also sensitized to mites, and vice versa. We also found that participants who were sensitized to both shrimp and mites were more likely to have respiratory symptoms, angioedema, and airflow limitation.

Our results suggest that patients presenting symptoms of shrimp or mite allergy should be examined for sensitization and allergy to both allergens. These results are also relevant when introducing new food products, such as insect-based foods, on the market, since insects express the muscle protein tropomyosin, which is similar to the tropomyosin allergens found in shrimp and mites.

\section{Funding sources}

The main funding body of the Swedish CArdioPulmonary bioImage Study is the Swedish Heart and Lung Foundation. Thermo Fisher Scientific performed the specific IgE testing within a research collaboration agreement with Uppsala University. IW is supported by FORMAS grant number 2018-00945.

\section{References}

1. Johnson J, Borres MP, Nordvall L, Lidholm J, Janson C, Alving K, Malinovschi A. Perceived food hypersensitivity relates to poor asthma control and quality of life in young non-atopic asthmatics. PLoS One . 2015;10(4):e0124675.

2. Santos AB, Chapman MD, Aalberse RC, Vailes LD, Ferriani VP, Oliver C, Rizzo MC, Naspitz CK, Arruda LK. Cockroach allergens and asthma in Brazil: identification of tropomyosin as a major allergen with potential cross-reactivity with mite and shrimp allergens., J. Allergy Clin. Immunol . 1999;104(2):329-337.

3. Broekman HCHP, Knulst AC, de Jong G, Gaspari M, den Hartog Jager CF, Houben GF, Verhoeckx KCM. Is mealworm or shrimp allergy indicative for food allergy to insects? Mol Nutr Food Res. 217;61(9):1601061.

4. Bergstrom, G., et al . The Swedish CArdioPulmonary BioImage Study: objectives and design. $J$ Intern Med. 2015;278(6):645-59.

5. Zaigham S, Zhou X, Molin M, Sjölander A, Movérare R, Janson C, Malinovschi A. Importance of type and degree of IgE sensitization for defining fractional exhaled nitric oxide reference values.Respir Med. 2021;188:106621. 